\title{
Outdoor chemistry in teacher education - a case study about finding carbohydrates in nature
}

\author{
Jan Höper and Hans-Georg Köller
}

UiT The Arctic University of Norway

\begin{abstract}
In this case study, we describe an inquiry-based approach to enhancing tuition in chemistry by taking student teachers out of the lab and into nature. We used video observation and interviews to gain insight into student teachers' expectations and experiences of such fieldwork. Through thematic analysis, we found that the participants perceived the approach as individually relevant and worthy of integrating as a teaching method in future practice. Further, we discussed challenges presented by outdoor chemistry and ways to overcome these. Overall, we show that fieldwork in chemistry contributed to a better understanding of chemistry as an integral part of nature.
\end{abstract}

Keywords: inquiry-based, linking domains, outdoor chemistry, outdoor learning, relevance

Contact: jan.hoper@uit.no

DOI: https:/ / doi.org/ 10.31129/ LUMAT.6.2.314

\section{Introduction}

School students rarely perceive chemistry lessons as relevant or motivating (Sjøberg \& Schreiner, 2010). In many cases, concepts are presented in an abstract way and in a strange and unfamiliar language. All too often, they are related neither to the students' lives nor to the world they live in (Childs, Hayes \&O'Dwyer, 2015). A recent study confirms the challenge in attitudes among students towards different fields of science, with chemistry generally viewed as "toxic", whereas nature is perceived as "idyllic" (Krischer, Spitzer \& Gröger, 2016). Suggested approaches to making school chemistry more relevant include teaching chemistry in realistic contexts by employing everyday-products (Gilbert, 2006; Parchmann et al., 2006). Another possibility is emphasizing education for sustainable development (Burmeister, Rauch \& Eilks, 2012; J egstad \& Sinnes, 2015). Still, chemical substances are mostly examined in the laboratory, often separated from their normal range of use or occurrence, leading to critiqueand calls to take chemistry out of the classroom (Ceci, 2015). Here we describe an approach to outdoor chemistry that was inspired by the concept of "chemistry trails" (Borrows, 2006). 


\subsection{Theoretical background}

School-based outdoor teaching of chemistry is a rare occurrence, and is mostly confined to the context of larger projects within geology or biology, or to visiting external resources such as factories, semi-natural outdoor-labs or science centers (Burmeister et al., 2012; Gröger, 2013; Thorsheim, Kolstø \& Andresen, 2016). Our proposed approach to outdoor chemistry consists of short field trips that are compatible with a normal chemistry curriculum, thus creating a low threshold for teachers to take chemistry outside. Thorburn \& Allison (2010, p. 101) discuss the benefits of such an approach as "low in risk and high in transfer value", compared to outdoor center visits, which are often "disassociated from current school-based learning contexts and lacking in transferable value". Instead of traditional teachercentered excursions, we propose active student-led learning outside the classroom or laboratory. Our approach is based on sequences of outdoor experiments that are fast (5-45 minutes), simple, and require collaborative work. This allows science teaching to become more relevant, thereby fostering deeper learning. This was also demonstrated in a new framework for the "extended classroom" (Remmen \& Frøyland, 2017).

Relevance is a commonly used term in connection with curriculum development and in science education research. However, in many cases the conceptualization of relevance is inadequate. In our analysis, we use the model of three dimensions of relevance, suggested by Stuckey, Hofstein, Mamlok-Naaman \& Eilks (2013). The individual dimension incorporates aspects like personal interest, new knowledge and comprehension or achieving good marks. The societal dimension includes different aspects about the individual's place and behavior in society. The vocational dimension focuses on aspects relevant for the students' future professional development. Within each of these dimensions, there are components of relevance, ranked along a presentfuture and an intrinsic-extrinsic range (ibid.).

The benefits of outdoor teaching, when well planned and coordinated, have been documented (Dillon \& Dickie, 2012; Dillon et al., 2006; Fiennes et al., 2015; Glackin, 2016). Fieldwork "offers learners opportunities to develop their knowledge and skills in ways that add value to their everyday experiences in the classroom." (Dillon et al., 2006, p. 107). Scott et al. (2012) show similar effects for students in higher education. At the same time, there are challenges related to achieving the intended learning outcomes through practical work. For example, it has been argued that practical work 
can involve a lot of physical, but not enough cognitive activity and suffer from a lack of focus (Abrahams \& Millar, 2008; Remmen \& Frøyland, 2017).

In this context, Abrahams \& Millar (2008, p. 1948) state that "the fundamental purpose of practical work in school science is to help students make links between the real world of objects, materials and events, and the abstract world of thoughts and ideas". However, it has been shown that students need considerable help to actually make links between these two worlds, which represent two domains of knowledge (ibid.). Scott, Mortimer \&Ametller (2011, p. 5) state: "It is clear that if link-making is not addressed through teaching, then it is unlikely to emerge in students' learning." Three forms of pedagogical link making that foster learning were identified: supporting knowledge building, promoting continuity and encouraging emotional engagement (ibid.). Misconceptions may impede link-making. We follow the definition of misconceptions as misunderstandings, formed after formal teaching in the subject, compared to those before formal teaching (pre-concepts) (Stojanovska, Petrusevski, Köller \& Karlsen, 2015). Such misconceptions, held by students at different levels, from school to university, have to be identified first, and in the next step addressed and challenged (Abell, 2007).

In addition to the challenges mentioned above, teachers perceive different specific challenges that keep them from doing fieldwork (Glackin, 2016). Common reasons include "inflexible and overcrowded curriculum, resource shortage, safety issues, lack of teacher confidence and expertise, poorly designed school grounds that limit use, lack of pupil interest, and unsuitable weather", as described by Fägerstam (2014, p. 59).

\subsection{Research questions}

Based on the theoretical background presented above, we developed the following research questions:

- How do outdoor lessons influence student teachers' understanding of chemistry as an integrated part of nature outside the chemistry-lab?

- What are the student teachers' expectations and experiences with regards to the fieldwork itself and with regards to integrating it into their future teaching? 


\section{Method}

\subsection{The teaching unit}

This case study was conducted in an integrated science course, preparing student teachers for teaching years 5-10 of secondary school in Norway. In this country, science, technology and engineering are combined in one subject ("Naturfag") up to 11th grade, (Utdanningsdirektoratet, 2017). Here we follow five student teachers ("students 1-5") and one in-service teacher in continuing education ("student 6") whilst they carry out fieldwork. The student teachers mainly worked in two groups, called group A (student 1-3) and group B (student 4-6).

The case study was embedded in an inquiry-based teaching unit about food chemistry. The summary in Figure 1 illustrates how we integrated the fieldwork into the existing chemistry curriculum by replacing parts of teaching units in the lab with outdoor sequences. The students were set the task of acting as "molecule detectives" and equipped with "chemistry tool bags", which contained the necessary equipment in the form of easy to use test kits, in this case glucose test strips and Lugol's solution (starch test), Figure 2.

The main learning objectives were to find carbohydrates in nearby nature, coupled with reflecting on how to implement similar approaches in their own future teaching practice. Step-by-step guidelines for the outdoor teaching unit are described for use in secondary school in Höper (2017). 


\section{Glucose - our main energy source}

Engage with the molecule

- Students measure and discuss blood glucose levels.

- They prepare and taste solutions with glucose concentrations like those in blood and apples.

Explore and explain properties of the molecule

- Introduce test strips as detection method and use on solutions.

- Introduce starch as a storage form for glucose; test a sample with the traditional I/KI-solution.

- Build glucose-molecules, joining them to a "starch molecule".

- Discuss properties on micro and macro level.

Investigating the abundance of glucose and starch in nature

Engage

- The Molecule detectives' assignment: Find glucose and starch in nature!

- Prepare fieldwork: Plan where to test and pack chemistry tool bags. Explore

- Fieldwork in nearby nature/gardens

Explain

- Compare test results with food databases.

- Present the results of the fieldwork.

Elaborate and evaluate

- Plenary discussion and follow-up questions

Scope of

the case

study

Figure 1. Summary of the teaching unit on glucose and other carbohydrates, based on the 5E inquiry-based instructional model (Bybee, 2009).

\subsection{Data collection}

To get a better understanding of the student teachers' perspective, we used a qualitative approach that incorporated data from different sources. We used video observation for a whole-class interview prior to the teaching unit, for the outdoor sequence and for a follow-on teaching sequence. During the outdoor sequence, we used chest mounted GoPro-cameras on one student per group (Frøyland, Remmen, Mork, Ødegaard \& Christiansen, 2015). Additionally, we audio-recorded individual, semi-structured interviews after the teaching unit (Kvale, Brinkmann, Anderssen \& Rygge, 2015).

The first author, who had been teaching the student teachers and therefore knew them well, continued as their teacher. The second author, who was not involved in 
this course, acted as an outside observer during the teaching unit and conducted the individual interviews without the presence of the first author.

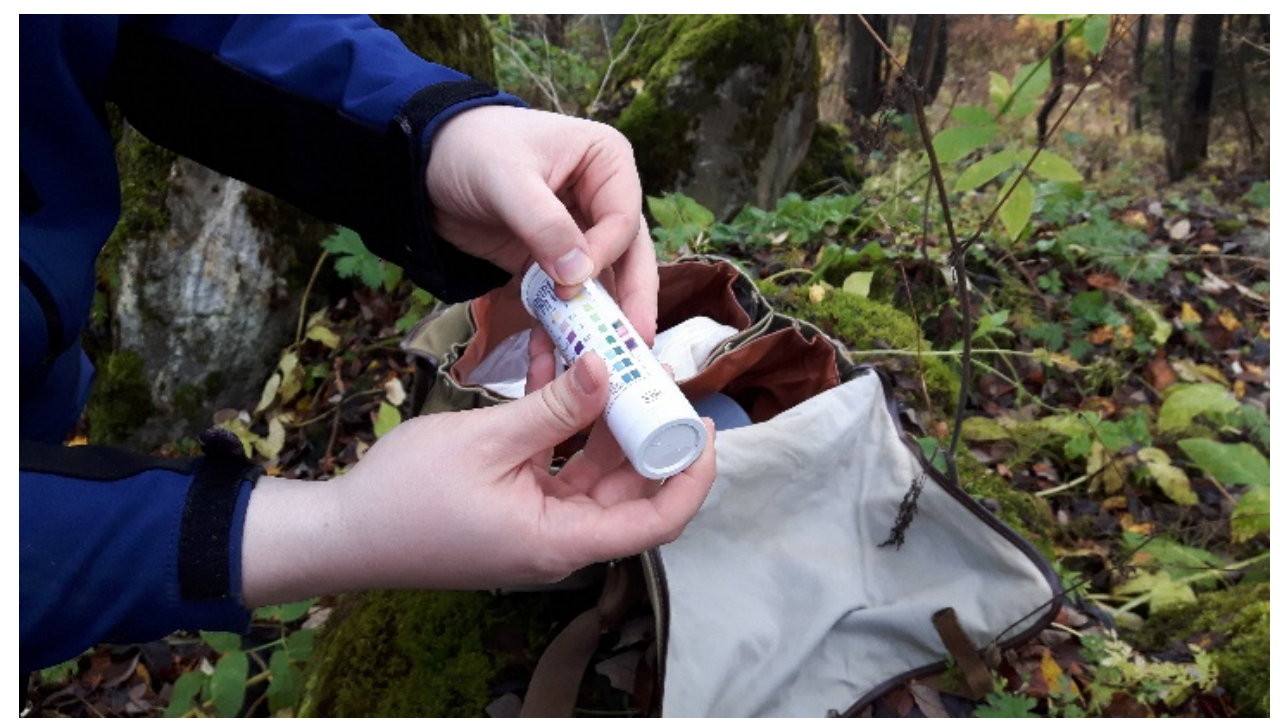

Figure 2. "Molecule detectives" outdoors, testing for glucose.

\subsection{Data analysis}

Our data analysis follows a thematic analysis approach (Braun \& Clarke, 2006). The analysis is based on 2 hours and 17 minutes of video footage and five individual interviews of approximately 20 minutes each. For practical reasons, it was not possible to interview student 6 . We used NVivo to transcribe the data word-for-word in Norwegian, including comments on important nonverbal events in the videos. Not every minute of video footage could be transcribed, though, due to technical challenges, for example when the groups were walking along a noisy road. Translation of quotes to English follows Norwegian closely.

After reading the transcripts, we developed an initial codebook. Intercoder agreement was reached by iteratively double coding parts of the transcripts, followed by comparing and revisiting our codes (Creswell, 2013). The transcripts alone did not cover details of the voices, intonation and other nonverbal activities, which we realized were necessary to set short dialogues into context. Therefore, we compared and discussed remaining disagreements with regards to coding by using the transcripts together with raw footage in NVivo, as this gave us a more nuanced understanding. In addition, we discussed our article with our research group, as suggested by Creswell (2013). 
By reading the transcripts repeatedly, comparing the codes and data-extracts with literature shown in the introduction, we thematically classified three themes, divided into eight sub-themes, as summarized in Table 1. The first theme concerns the relevance for the individual and vocational dimensions as defined by Stuckey et al. (2013). The second theme addresses challenges that the student teachers show throughout our material, both during fieldwork and in the interviews. These were comparable to those described in related work (e.g. Fägerstam, 2014). Therefore, we decided to define them being a theme themselves. The third theme contains observations concerning the relationship between school chemistry and real life experiences (e.g. Krischer et al., 2016). In our material, we see link-making (or sometimes a lack of link-making), as defined in Scott et al. (2011), as crucial. The teacher students were establishing links between different domains of knowledge (Abrahams \& Millar, 2008).

Table 1. Themes and sub-themes

\begin{tabular}{ll}
\hline Theme & Sub-theme \\
\hline Relevance & Individual \\
& Vocational \\
Challenges & Practical and methodological \\
& Learning outcomes \\
& Classroom management \\
Chemistry as an integrated part of & Linking organisms to chemical substances and their \\
nature & properties \\
& Linking the experiments to concepts in chemistry \\
& Linking organisms to content knowledge in biology \\
\hline
\end{tabular}

A short example to illustrate the key stages of our analysis is shown in Table 2. 
Table 2. Key stages of analysis of a segment of a dialogue. Situation: A group of student teachers discovers a bush of raspberries adjacent to a garden.

\begin{tabular}{|c|c|c|}
\hline Transcript excursion group A: & Initial coding & Sub-themes \\
\hline $\begin{array}{l}\text { Student 2: Shall we test them } \\
\text { immediately? [detaching the glucose } \\
\text { test strips from the tool bag] }\end{array}$ & $\rightarrow$ Hands on/ no challenges & $\begin{array}{l}\text { Vocational relevance } \\
\text { [easy to use in future } \\
\text { teaching practice] }\end{array}$ \\
\hline $\begin{array}{l}\text { Student 3: Yes. This is, [short pause] but } \\
\text { I don't know if it is important how ripe } \\
\text { they are? [short pause] }\end{array}$ & $\begin{array}{l}\rightarrow \text { Linking chemistry and } \\
\text { food } \\
\text { [referring to an earlier } \\
\text { dialogue about glucose } \\
\text { content in berries] }\end{array}$ & $\begin{array}{l}\text { Linking organisms to } \\
\text { chemical substances and } \\
\text { their properties }\end{array}$ \\
\hline $\begin{array}{l}\text { Student 3: Here is the flashback } \\
\text { [laughter] stealing raspberries! [whole } \\
\text { group laughing] }\end{array}$ & $\rightarrow$ childhood memories & Individual relevance \\
\hline Student 1: Yeah. [smiling] & & \\
\hline
\end{tabular}

\section{Results and discussion}

Following our research interest, we begin by discussing the student teacher's expectations and experiences, before addressing observations of learning experiences that allowed them to connect chemistry to nature. For the three themes defined above, we assessed combined data from the videos and the student teachers' interviews.

\subsection{Relevance}

The student teachers in our study perceived the approach to outdoor chemistry as relevant in both individual and vocational dimensions. We found no evidence in our data that the student teachers were preoccupied with the societal dimension of relevance (Stuckey et al., 2013).

\subsubsection{Individual relevance}

In the interviews, all student teachers described the approach as interesting and exciting:

Student 4: [...] more fun, you felt a little bit like a chemical Indiana J ones while you are outdoors and testing, bearing your little bag.

Nevertheless, it was not just fun. Most student teachers mentioned explicitly that it helped them to a better understanding of the subject matter: 
Student 5: [...] if I get a question about this in my exam, I will definitely remember it.

Student 1: I learnt something new on Friday. I am not so strong in chemistry.

The video-analysis of the outdoor sequence supports the findings from the interviews regarding individual relevance. The student teachers generally enjoyed the given tasks and were intrigued by the method of open inquiry. One student teacher had a particularly positive association of outdoor chemistry with his own childhood, repeatedly commenting on stealing raspberries ("bringebærslang"), spreading his excitement to the rest of the group (Table 2). "Bringebærslang" was his own wordcreation, adapted from a unique Scandinavian word for children stealing apples in the neighborhood ("epleslang”).

\subsubsection{Vocational relevance}

The student teachers had no previous experience of outdoor chemistry. Outdoor teaching was limited to biology or remembered as something they enjoyed, but without actual science content, e.g.:

Student 6: Well, I remember we were out a lot. In the forest, or at the beach below. I do not remember what the teaching content was about, but I remember the days clearly, I have very positive memories of being outside with school.

In the interviews carried out after the teaching unit, the student teachers discussed different aspects of the vocational dimension of relevance. They considered this approach as a new, meaningful tool, worth implementing into their own future science lessons:

Student 4: I now have this in a kind of "toolbox of ideas". I know this is a possibility. Now I will think more like - this is something I could do.

Observations during fieldwork confirmed statements like this. The student teachers eagerly tested the glucose concentration of many different organisms. The different dimensions of relevance in the model are interrelated and partly overlapping (Stuckey et al., 2013). Our data showed that student teachers often combined the individual and vocational dimension of relevance of the outdoor chemistry approach, describing it as personally intriguing and at the same time relevant for their future teaching practice. 


\subsection{Challenges}

We asked the student teachers about the challenges they expect for outdoor chemistry in their future teaching practice, while observing the challenges they encountered during the outdoor sequence. This was particularly interesting as none of the student teachers had previous experiences with outdoor chemistry. In our material, we thematically divided the challenges into three sub-themes.

\subsubsection{Practical-methodological challenges}

During the outdoor sequence, we observed that the student teachers often focused on practical aspects such as how to perform the tasks correctly and how to document the activities. In the following example, group A discusses how to optimize the documentation of the results, while at the same time considering methodological challenges:

Student 3: You might place it between them [Referring to the glucose test strip and the patches of the color scale]. It surely is a high value [short pause], but not full score.

Student 2: But, is it visible to the camera now? Exactly how much? Or should you take the picture this way? [trying different angles with a smartphone]

Student 3: We are keeping them, aren't we? [The used test strip] To look at them afterwards?

Student 2: But, they might change, don't they?

The example above confirms Fägerstam's (2014) findings for secondary school teachers that outdoor schooling facilitates experience-based learning. It also underlines the importance of outdoor experiments being easy to conduct. Student 6 (the in-service teacher) was fully aware of this, as expressed in the pre-interview:

Student 6: The tests have to be very easy if you want to do a lot outdoors, it has to be straightforward. It's no use to take out a lot of stuff.

Our approach seems to meet this criterion, as confirmed in the student teachers' follow-up interviews. Some of them mentioned the outdoor sequence as easier to conduct than expected (see vocational relevance above). 


\subsubsection{Learning outcomes}

It is difficult to draw a positive correlation between practical work and learning outcomes (e.g. Abrahams \& Millar, 2008; Hofstein \& Lunetta, 2004). Some of the student teachers reflected on this issue in their interviews:

Student 2: I think it can be difficult to ensure learning, learning what you intend for them to learn.

The importance of content knowledge prior to practical work, "to be able to derive meaning from their results”' (Köller, Olufsen, Stojanovska \& Petrusevski, 2015, p. 43), was evident during fieldwork. Student teachers struggled to make sense of some of the test results. This aspect was also discussed in theinterviews. One student explicitly mentioned not being familiar enough with the expected content knowledge.

Student 3: [hesitates] I don't grasp this fully, I really don't, but I understood the main principles.

Suggestions to overcome challenges regarding learning outcomes, as discussed by the student teachers, included adequate preparations, both practical and theoretical. They consider it important to have clear assignments to maintain a focused learning environment in school.

\subsubsection{Classroom management}

The student teachers were concerned about how to plan and organize outdoorsequences and stay in control, depending on the size of the school classes and the age of the students. At the same time, they suggested solutions like dividing the class into appropriately sized groups and selecting suitable outdoor locations to ensure a positive learning environment. They also expressed a belief in the benefits of the affective and social dimensions of outdoor learning, which had also been demonstrated in several previous studies (e.g. Fiennes et al., 2015).

All the aspects mentioned above are consistent with the findings of Fägerstam (2014), who investigated the perceived and experienced challenges by secondary school-teachers who participated in a one-year-program to implement outdoor schooling on a regular basis. They, too, expected that ensuring school student discipline would be tricky and indeed experienced this in the beginning, but they overcame this challenge and were able to focus on subject matter after a while. 
Surprisingly, in our case study, most of the students did not worry much about time as a limiting factor. This may be due to the students' lack of teaching experience and the positive reputation outdoor teaching has in their biology textbooks. Asked about the reason for not mentioning the issue of time, one student simply suggests combining lessons from science with other subjects to get more time. This pragmatic attitude might work, as we could actually observe it in Norwegian schools in different contexts, e.g. geology fieldwork combined with mathematics and physical education. Moreover, lack of time may not be a crucial issue as teachers can overcome this by reducing extended field trips to the nearby environment or even the school grounds (Fägerstam, 2014).

\subsection{Chemistry as an integrated part of nature}

We designed the teaching unit to help overcome "the cognitive challenge of linking observables to ideas" (Abrahams \& Millar, 2008, p. 1945) through executing chemical tests in situ, i.e. taking the lab out of the classroom, instead of the object of interest out of its context. Hereby, we identified three types of link-making between the domains of observables and the domains of ideas in our material.

\subsubsection{Linking organisms to chemical substances and their properties}

The main goal of this teaching approach was to link chemistry to nature, which we asked the students to reflect on in the interviews. Here are some examples:

Student 1: [...] it often becomes very "chemical" in the lab, you don't get any clues where to find these substances and this may be the most important thing: To get an opportunity to learn where to find them in nature.

In our data derived from fieldwork, we found interesting dialogues about where the student teachers expected to find the substances they should test. They also discussed other compounds like vitamins, or why tree bark might be nutritious. A misconception was revealed in group A in the interviews. We see the members of the group surprised about a negative test result for starch:

Student 2: Ok, but, eh.., we were sure there would be starch here, weren't we?

Student 1: Yes.

Student 3: Time will show. 
Student 2: [We expected] A lot. A lot in such nice food for moose.

Student 1: And...there was none [starch]!

Interesting details were discovered in the following interviews. One student teacher had never thought about the link between chemical substances and plants:

Researcher: Was there anything extra exciting? Maybe something you didn't know before?

Student 3: There was a revelation; I didn't expect it [bark, expl. note authors] would be made of carbon compounds. I had never heard that living organisms are made of that, trees and such.

Later in the interview, we talked about different carbohydrates:

Student 3: [...] really, I thought about glucose, that it tastes sweet and would be liquid, that's what I thought. And starch more like.. I don't know, maybe I was a little bit confused there..I thought about starch, assumed it would be something solid.

Researcher: Yes, OK.

Student 3: I had this in my mind. I don't think I understood it properly on a molecular level before we went out.

Outdoor sequences can help to identify these kinds of misconceptions, as they may offer an experience "so out of the normal run of experience that it requires a drastic re-appraisal of what we think we know" (Waite, 2017, p. 16).

The student teachers were very surprised about the negative test results for starch, as shown in the dialogue above. They thought that bark is made of starch. Obviously, the student teachers held a misconception, which to some extent was derived from the Norwegian word for starch that one might associate with something being stiff or strong. Student 3 did not consider the concept of chemical substances in living organisms before the outdoor sequence at all. Moreover, students 1 and 2 did not have sufficient knowledge of the differences between common polysaccharides, as the individual interviews showed. These misconceptions were addressed afterwards, and the student teachers realized that their original hypothesis would have made sense if they had expected cellulose instead of starch. All the students in group A achieved a better understanding of biopolymers as the building blocks of organisms. According to Scott et al. (2011), it is important to provide opportunities that foster link-making 
between real world phenomena and theoretical content. This seems to apply not only for school students, but for student teachers as well.

\subsubsection{Linking the experiments to concepts in chemistry}

During the outdoor sequence, student teachers were frequently preoccupied with practical issues, as shown in the section about challenges. Nevertheless, reflections about concepts in chemistry, such as solubility and concentration, were observed on different occasions. We observed informal and explicit learning processes about the properties of the chemical compounds. When testing resin, one of the students tried to get rid of it by washing it with water and learned hands-on that this wasn't possible. Also, student teachers discussed the solubility of glucose, when thinking about using water on a plant extract to get enough liquid for the test:

Student 2: But - eh - if we take a lot of water [thinking for a while] doesn't that affect something?

Student 1: Sure. There will be glucose in the water. Water-soluble.

Student 2: Yes. It will be lesser concentrated if we take a lot of water. If we use a lot of water [thinking for a while], we have to take that into consideration.

This quote may serve as an example for one of the suggested approaches to support knowledge building, namely "making links between scientific explanations and real world phenomena" (Scott et al., 2011, p. 9). In this case, it is student 2, who is actively making a new link, as "it is necessary for the learner to carry out the process of linkmaking for themselves" (ibid., p 4).

Student teachers in group B engaged in discussing the quantitative results and sometimes asked the teacher for help:

Student 6: [looking at the test scale, comparing colours] How about this one? The 1...ish? Percent, isn't it?

Teacher: Percent, yes.

Student 6: Yes. [thinking for a while] 56. [thinking for a while] Which means $56 \mathrm{mmol} / \mathrm{L}$, yes. [thinking for a while] Yeah, that looks reasonable, doesn't it?

In the last sentence, student 6 was referring to glucose concentrations that had been prepared by the student teachers earlier that day. Wealso notice the role of the teacher 
here, as described in Thorsheim et al. (2016). Even if student 6 technically knows the correct answer, confirmation is sought from the teacher before extrapolating from the observation and establishing the link between the visible test results and actual glucose concentrations.

\subsubsection{Linking organisms to content knowledge in biology}

On several occasions, student teachers talked about species names, trying to remember fieldwork from an introductory course. Some of them revealed a low level of knowledge of biodiversity, talking about "grass" and "all the green leaves", without remembering more than the names of common tree species. At the same time, they are clarifying their own concepts:

Student 3: Bark, that is spruce and pine, and such things, isn't it? "Never" [birch bark in Norwegian; expl. authors] sure is birch, and...

Student 1: No, it isn't! [Researcher agrees to student 1 by shaking his head.]

Student 3: Is it the same stuff? The same, and only different names for it?

These dialogues emphasize two points. Firstly, much of what is taught in the early stages of teacher training can be categorized as rotelearning, which is easily forgotten after the exams (ibid.). Secondly, if we want our students to achieve meaningful learning, including a more holistic understanding of science, repeated excursions in the same environment, with different starting points and relevant assignments, could be useful (Remmen \&Frøyland, 2017). This provides opportunities to ensure a deeper understanding by connecting theoretical concepts to a rich learning environment, thereby fostering pedagogical link making (Scott et al., 2011). The dialogue about bark, for instance, continued into a broader discussion about ruminants and bacteria that would help moose, a common animal in Scandinavian forests, to digest bark.

In the end, only student 6 (the in-service teacher) explicitly linked different domains of ideas during the fieldwork:

Student 6: Thinking about it - there should be glucose in leaves, if, if photosynthesis. If the product of photosynthesis is glucose!

School students, but also student teachers, may need considerable help from their teachers or peers to be able to link the different domains of observables and ideas (Abrahams \&Millar, 2008). This applies to chemistry in particular: "This strangeness 
and lack of connection to real life is greater for chemistry than it is for biology and physics, where students have more immediate and obvious contact with the subject matter" (Childs et al., 2015).

As a final comment, it is of note that seemingly easy concepts raise a number of questions when taken out of the textbook and into a real-life context. The nature of the student teachers' textbook is likely to play a crucial role here, as formulas of carbohydrates were presented without any clear links to a real-life context. This emphasizes the learning potential of integrating fieldwork into chemistry lessons, especially for teachers who will face all kinds of basic questions from school students. This is in line with a statement from Borrows (2006, p. 24): "Even well-qualified chemistry graduates may find they do not have much factual knowledge of their chemical environment but can readily understand and build on it once the ideas are pointed out."

\section{Conclusions and implications}

The aim of this case study was to analyze how student teachers experienced a new approach to outdoor chemistry teaching.

Concerning the different dimensions of relevance experienced by the student teachers with regards to the fieldwork, many expressed during the interviews that they found both personal and vocational relevance in the exercise, and we found evidence for this when analyzing the footage of the field work. The student teachers perceived the outdoor sequence as personally intriguing whilst also providing a useful method to meet educational demands. Overall, they considered the approach worth taking into consideration when planning chemistry education in their future practice in secondary school.

Furthermore, the student teachers showed a generally critical and realistic attitude towards the different types of challenges they expected from and experienced during the fieldwork in chemistry. They dealt with these in a positive, solution-oriented way.

Finally, in our case study the student teachers linked three different types of domains of observables to domains of ideas. They directly made connections between organisms and chemical substances, linked the experiments to chemical concepts and linked organisms to a spectrum of biological content knowledge. Nevertheless, we also found misconceptions in the students' understanding of organic chemistry in 
organisms, which would likely never have been articulated and reflected on if they had studied and worked in the lab exclusively.

Findings discussed in this article show that fieldwork in chemistry provides a rich learning environment, enabling student teachers with deep content knowledge to utilize in a new, vocationally relevant context. Other student teachers may get basic, but important insights when connecting chemistry to nature.

This limited case-study shows that introducing small excursions into the chemistry curriculum can be relevant on two levels, both for the student teachers' own understanding of the subject matter and as a tool for their future teaching practice. Additionally, they get the opportunity to reflect on the difference of working with defined chemicals in the lab versus working with real-life reservoirs of the same substances. However, outdoor teaching units have to be followed up with reflective teaching sequences to ensure that they result in intended learning outcomes, as evident from the individual interviews with the student teachers.

\section{References}

Abell, S. K. (2007). Research on science teacher knowledge. In S. K. Abell \& N. G. Lederman (Eds.), Handbook of research on science education. London: Lawrence Erlbaum.

Abrahams, I., \& Millar, R. (2008). Does Practical Work Really Work? A Study of the Effectiveness of Practical Work as a Teaching and Learning Method in School Science. International J ournal of Science Education, 30(14), 1945-1969. doi:10.1080/09500690701749305

Höper, J . (2017). Natural experiments: Taking the lab outdoors. Science in School (42), 42-48. Borrows, P. (2006). Chemistry outdoors. School science review, 87(320), 23-31.

Braun, V. \& Clarke, V. (2006). Using thematic analysis in psychology. Qualitative Research in Psychology, 3(2), 77-101. doi:10.1191/ 1478088706qp063oa

Burmeister, M., Rauch, F. \&Eilks, I. (2012). Education for Sustainable Development (ESD) and Chemistry Education. Chemistry Education Research and Practice, 13(2), 59-68. doi:10.1039/C1RP90060A

Bybee, R. W. (2009). The BSCS 5E instructional model and 21st century skills. Retrieved from: http:// sites.nationalacademies.org/cs/ groups/ dbassesite/ documents/ webpage/ dbasse_07 3327.pdf

Ceci, C. (2015). Take concepts of chemistry out of the classroom. Nature, 522(7554), 7. doi: $10.1038 / 522007 a$

Childs, P. E., Hayes, S. M., \&O’Dwyer, A. (2015). Chemistry and Everyday Life: Relating Secondary School Chemistry to the Current and Future Lives of Students. In I. Eilks \&A. Hofstein (Eds.), Relevant Chemistry Education: From Theory to Practice (pp. 33-54). Rotterdam: SensePublishers.

Creswell, J . (2013). Qualitative inquiry \& research design: Choosing among five approaches (3rd ed.). Los Angeles: Sage. 
Dillon, J . \& Dickie, I. (2012). Learning in the Natural Environment: Review of social and economic benefits and barriers. Natural England Commissioned Reports(092).

Dillon, J ., Rickinson, M., Teamey, K., Morris, M., Choi, M. Y., Sanders, D. \& Benefield, P. (2006). The value of outdoor learning: evidence from research in the UK and elsewhere. School science review, 87(320), 107-111.

Fiennes, C., Oliver, E., Dickson, K., Escobar, D., Romans, A. \& Oliver, S. (2015). The Existing Evidence-Base about the Effectiveness of Outdoor Learning. Institute of Outdoor Learning, Blagrave Trust, UCL \& Giving Evidence Report.

Frøyland, M., Remmen, K. B., Mork, S. M., Ødegaard, M. \& Christiansen, T. (2015). Researching science learning from students'view; the potential of headcam. Nordina, 11(3), 249-267.

Fägerstam, E. (2014). High school teachers' experience of the educational potential of outdoor teaching and learning. J ournal of Adventure Education and Outdoor Learning, 14(1), 5681. doi:10.1080/14729679.2013.769887

Gilbert, J . K. (2006). On the Nature of "Context" in Chemical Education. International J ournal of Science Education, 28(9), 957-976. doi: 10.1080/ 09500690600702470

Glackin, M. (2016). 'Risky fun' or 'Authentic science'? How teachers' beliefs influence their practice during a professional development programme on outdoor learning. International J ournal of Science Education, 38(3), 409-433. doi:10.1080/09500693.2016.1145368

Gröger, M. (2013). Teaching chemistry in near-natural learning environments to address sustainability. Paper presented at the ESERA 2013 Conference, Strand 9 Environmental, health and outdoor science education, Nicosia.

Hofstein, A., \&Lunetta, V. N. (2004). The laboratory in science education: Foundations for the twenty-first century. Science Education, 88(1), 28-54. doi:10.1002/ sce.10106

J egstad, K. M. \& Sinnes, A. T. (2015). Chemistry Teaching for the Future: A model for secondary chemistry education for sustainable development. International J ournal of Science Education, 37(4), 655-683. doi:10.1080/09500693.2014.1003988

Krischer, D., Spitzer, P. \& Gröger, M. (2016). “Chemistry is Toxic, Nature is Idyllic” - Investigation of Pupils' Attitudes. The J ournal of Health, Environment, \& Education, 8, 7-13.

Kvale, S., Brinkmann, S., Anderssen, T. M. \& Rygge, J . (2015). Det kvalitative forskningsintervju (3. utg., 2. oppl. ed.). Oslo: Gyldendal akademisk.

Köller, H.-G., Olufsen, M., Stojanovska, M. \& Petrusevski, V. (2015). Practical work in chemistry and its goals and effects. Chemistry in Action(106), 37-50.

Parchmann, I. , Gräsel, C. , Baer, A. , Nentwig, P., Demuth, R. \& Bernd Ralle the ChiK Project Group (2006). “Chemie im Kontext”: A symbiotic implementation of a context - based teaching and learning approach. International J ournal of Science Education, 28(9), 10411062. doi: 10.1080/09500690600702512

Remmen, K. B. \& Frøyland, M. (2017). «Utvidet klasserom» - Et verktøy for å designe uteundervisning i naturfag. Nordina, 2, 218-229.

Scott, G. W., Goulder, R., Wheeler, P., Scott, L. J ., Tobin, M. L. \& Marsham, S. (2012). The Value of Fieldwork in Life and Environmental Sciences in the Context of Higher Education: A Case Study in Learning About Biodiversity. J ournal of Science Education and Technology, 21(1), 11-21. doi:10.1007/s10956-010-9276-x

Scott, P., Mortimer, E. \&Ametller, J . (2011). Pedagogical link-making: A fundamental aspect of teaching and learning scientific conceptual knowledge. Studies in Science Education, 47(1), 3-36. doi:10.1080/03057267.2011.549619

Sjøberg, S., \& Schreiner, C. (2010). The ROSE project: An overview and key findings. Retrieved from https:/ / roseproject.no/ network/ countries/ norway/ eng/ nor-Sjoberg-Schreineroverview-2010.pdf 
Stojanovska, M., Petrusevski, V., Köller, H. G. \& Karlsen, S. (2015). Students' alternative conceptions and ways to overcome them. In I. Maciejowska \& B. Byers (Eds.), A guidebook of good practice for the pre-service training of chemistry teachers. Krakow: J agiellonian University.

Stuckey, M., Hofstein, A., Mamlok-Naaman, R. \& Eilks, I. (2013). The meaning of 'relevance' in science education and its implications for the science curriculum. Studies in Science Education, 49(1), 1-34. doi:10.1080/03057267.2013.802463

Thorburn, M. \&Allison, P. (2010). Are we ready to go outdoors now? The prospects for outdoor education during a period of curriculum renewal in Scotland. The Curriculum J ournal, 21(1), 97-108. doi:10.1080/ 09585170903560824

Thorsheim, F., Kolstø, S. D. \&Andresen, M. U. (2016). Erfaringsbasert læring : naturfagdidaktikk. Bergen: Fagbokforl.

Utdanningsdirektoratet (2017). Natural Science subject curriculum (NAT1-03). Retrieved from https:/ / www.udir.no/ k106/ NAT1-03?lplang=http:/ / data.udir.no/kl06/ eng [September 20, 2017].

Waite, S. (2017). Children learning outside the classroom: From birth to eleven (second ed.). London: Sage. 